\title{
Herbal Medicines in the Treatment of Psychiatric Disorders:
}

\section{0-year updated review}

\author{
Jerome Sarris, $\mathrm{PhD}, \mathrm{MHSc}^{, 1,2}$ \\ ${ }^{1}$ NICM, School of Science and Health, Western Sydney University, Australia \\ 2 The University of Melbourne, Department of Psychiatry, The Melbourne Clinic, \\ Professorial Unit, ARCADIA Research Group, Melbourne, Australia
}

Word Count: 8500

Tables: 2

\section{Correspondence:}

Prof Jerome Sarris

NICM, Western Sydney University

Locked Bag 1797, Penrith, NSW 2751, Australia

Ph: + 61246203326 E: jsarris@westernsydney.edu.au

This is the author manuscript accepted for publication and has undergone full peer review but has not been through the copyediting, typesetting, pagination and proofreading process, which may lead to differences between this version and the Version of Record. Please cite this article as doi: $10.1002 /$ ptr.6055

This article is protected by copyright. All rights reserved. 


\section{ABSTRACT}

This paper provides a 10-year update of the 2007 systematic review of herbal medicines studied in a broad range of psychiatric disorders, including depression, anxiety, obsessive-compulsive, seasonal affective, bipolar, psychotic, phobic, somatoform, and attention-deficit hyperactivity disorders. Ovid Medline, PubMed and the Cochrane Library were searched for herbal medicines with both pharmacological and clinical evidence of psychotropic activity. This updated review now covers clinical trial evidence for 24 herbal medicines in 11 psychiatric disorders. High-quality evidence was found to exist for the use of Piper methysticum (Kava), Passiflora spp. (Passionflower) and Galphimia glauca (Galphimia) for anxiety disorders; and Hypericum perforatum (St John's wort) and Crocus sativus (Saffron) for major depressive disorder. Other encouraging herbal medicines with preliminary evidence include Curcuma longa (Tumeric) in depression, Withania somnifera (Ashwagandha) in affective disorders, and Ginkgo biloba (Ginkgo) as an

adjunctive treatment in Schizophrenia. While depression and anxiety are commonly researched, many other mental disorders still require further prospective investigation. While the previous review suggested for increasing adjunctive study of select herbal medicines with pharmaceuticals; this was still only found to sparingly occur in research designs. Aside from this, future focus should involve the incorporation of more biomarker analysis, in particular pharmacogenomics, to determine genetic factors moderating response to herbal medicines.

This article is protected by copyright. All rights reserved. 
Key Words: herbal medicine; medicinal plants; psychiatry; psychiatric disorders; depression; mood disorders; anxiety; clinical trials

Running Header: Herbal Medicines for Psychiatric Disorders

This article is protected by copyright. All rights reserved. 


\section{INTRODUCTION}

The role of herbal medicine in the treatment of various psychiatric disorders has become more established over the past decade, with phytotherapeutic preparations such as Hypericum perforatum (St John's wort) and Piper methysticum (Kava) possessing respectable clinical evidence. In 2007, due to the previous deficit of broad and comprehensive reviews (aside from the light review by Wong et. al. (Wong et al., 1998)) a systematic review of herbal medicines across a breadth of psychiatric disorders was conducted (Sarris, 2007). Twenty seven plant medicines were originally reviewed in 2007 using a rudimentary systematic literature search used to identify relevant trials of herbal medicines in the treatment of major psychiatric disorders. A summary of that review revealed that a range of plant medicines indicated potential efficacy, however aside from Kava and St John's wort, many of these medicines featured only in isolated small sample studies.

The purpose of this narrative systematic review is to provide a 10-year update of the research in the field, to investigate and detail further research that has been conducted. This review employs a tightened and more targeted inclusion criteria in order to succinctly synthesise the evidence, and to provide more room to discuss any key developments in the field, and areas still needing research attention. This update is also of importance given the revision of the Diagnostic and Statistical Manual for Psychiatric Disorders to edition 5 (APA, 2013).

\section{METHODS}


The specific focus of this review was to locate human studies involving herbal medicines for the treatment of major psychiatric disorders or mental health symptoms (secondary mental health outcome data from non-psychiatric disorder studies were omitted). To this end, the electronic databases Ovid Medline, PubMed and The Cochrane Library were originally accessed in early 2007; with an updated search occurring during September to October 2017. Ovid Medline was searched using the search term 'Herb\$' and the subheadings 'Plants, Medicinal', 'Plant Extracts', 'Phytotherapy', 'Plant Preparations' in combination with the search terms ‘Depress\$', 'Major Depressive Disorder', 'Anxiety', 'Generalized Anxiety Disorder', 'Dysthym\$', 'Seasonal Affective Disorder', 'Bipolar Disorder', 'Panic Disorder', 'Phobi\$', 'Obsessive Compulsive Disorder', 'Somatoform Disorder', 'Schizophrenia and 'Psychotic Disorder'. PubMed and Cochrane databases were accessed, with MeSH being employed to search major psychiatric topics 'Depressive Disorder', 'Depression', ‘Dysthymic disorder', 'Bipolar Disorder', 'Anxiety', 'Anxiety Disorders', 'Phobic Disorders', 'Panic Disorder', 'Seasonal Affective Disorder', 'Somatoform Disorders', 'Psychotic Disorders', 'Schizophrenia', Attention Deficit Hyperactivity Disorder, in combination with the MeSH terms, 'Plants, Medicinal, 'Plant extracts', 'Phytotherapy'. A forward search of the papers reviewed was subsequently performed using Web of Science cited reference search. Herbal medicines with known traditional or modern usage were also individually reviewed in PubMed and Ovid databases by conducting a search using the name of the herbal medicines e.g. 'St John's wort' OR ‘Hypericum'. 
An assessment based on the hierarchy of evidence was undertaken, with metaanalyses and randomised controlled human clinical trials (RCTs) reviewed where possible (Altman et al., 2001, Gagnier et al., 2006). Non-randomised or nonplacebo-controlled human trials were reviewed where there was also preclinical data. In vitro studies were only reviewed to assess safety data, constituents responsible for activity, or to further determine use. A primary focus was on evidence concerning whole herbal extracts (rather than isolated constituents) as this use occurs in standard phytotherapeutic practice. Studies using intravenous, topical, or inhalant administration were excluded, as these methods do not reflect oral pharmacokinetics and subsequent pharmacodynamic activity which occur from per os delivery in humans.

The major change in this updated review is that traditional Chinese or Kampo formulas found in the original search (Xiaoyao, Gan Mai Da Zao, Chaihu-ShuganSan, Shuganjieyum Ganmia Dazao, Gamisoyo-San, Yokukasan, Wuling, Saibokuto, Sho-ju-sen, Suanzaorentang, Ting-chih-wan, and Banxia houpu) were not detailed in this review, as the literature has increased markedly in the past decade in this area, and a separate systematic review of these formulas is advised. Studies involving targeted combinations of herbal medicine e.g. Valerian and Kava for anxiety, were however included. Studies on isolated constituents were not included unless when referencing understanding of the active constituents (and aside from curcumin, which is considered to be the primary active constituent of Tumeric [a similar position could be taken regarding Milk Thistle research when assessing studies using silymarin]), Due to this, certain plant medicines and formulas were 
removed from this update, in addition to the mention of Echium anoemun (Borage) due to safety concerns.

Studies detailing secondary analyses of the primary data were not included due to word limits. A new section on Attention Deficit Hyperactivity Disorder (ADHD) is also added, however developmental, cognitive/ neurological (unless within a psychiatric disorder), sleep, eating, substance-abuse disorders, and menstrual dysphoria were still excluded from the review due to manuscript size constraints. The final change was truncation in the introductory sections of the disorder descriptors (e.g. diagnosis, prevalence, cost) in order to provide more space for discussion of the herbal medicine literature. For ease of reading, the raw statistics are omitted, with 'significant' effects reflecting a $p$ value of $<0.05$.

\section{Tables 1 and 2 about here}

\section{OVERVIEW OF THE DATA}

The updated review revealed 24 individual herbal medicines being used for 11 psychiatric conditions (see Table 1 and 2 below for the list of herbal medicine and psychiatric conditions reviewed (cf. (Sarris et al., 2011) for a table summarising constituents and psychopharmacology). Meta-analyses were available for three herbal medicines (Crocus sativus [Saffron]; St John's wort; Kava). A succinct summary of the data is provided below, covered under the major psychiatric disorder headings: 


\section{MOOD DISORDERS}

\section{Major depressive disorder (MDD)}

MDD or 'unipolar depression' involves depressed mood or reduced interest or pleasure, and is accompanied by at least four other additional symptoms (e.g. weight or appetite change, fatigue, psychomotor agitation, insomnia or hypersomnia, lack of concentration, suicidal ideation, feelings of worthlessness or guilt and low libido (APA, 2013). According to the World Health Organization (WHO), an estimated 322 million people are currently effected by MDD (including dysthymia), an increase of more than $18 \%$ over the ten-year period since 2005 , making it the leading cause of ill health and disability worldwide (WHO (WHO, 2006). MDD is the psychiatric condition in which the most herbal medicine research has been conducted, with St John's wort representing the vast majority of the research.

\section{Crocus sativus (Saffron)}

Saffron has been used to improve mood in traditional Persian medicine, with a continual flow of RCTs being conducted in Iran in the past 12 years. Saffron stigma contain an estimated 40 to 50 active therapeutic constituents with high quality saffron containing approximately 30\% crocins, 5-15\% picrocrocin, and over 5\% volatile compounds including safranal (Schmidt et al., 2007). In respect to 
mechanisms of action, preclinical animal models using ethanolic extracts of saffron and its constituents safranal and crocin, have shown antidepressant, anxiolytic, and hypnotic effects (Hosseinzadeh and Noraei, 2009). Crocin's antidepressant activity purportedly acts via re-uptake inhibition of dopamine and norepinephrine, and safranal's via serotonin reuptake inhibition (Schmidt et al., 2007). Anti-inflammatory and immunological effects have also been revealed in preclinical models (Boskabady and Farkhondeh, 2016, Chiavaroli et al., 2017).

A meta-analysis of published RCTs examining the effects of Saffron supplementation on symptoms of depression among participants with MDD was conducted in 2013. The criteria for study selection included adults (aged 18 and older) with symptoms of depression, RCTs (versus placebo or an antidepressant), assessing the effects on depressive symptoms (Hausenblas et al., 2013). A total of five RCTs were located (two placebo controlled trials, and three antidepressantcontrolled trials). A significant result with a large effect size was found in favour of Saffron treatment vs placebo control in treating depressive symptoms, while no significant difference was evidenced between Saffron prescription and the antidepressant groups, indicating that both treatments were similarly effective in reducing depression symptoms. The mean Jadad score was 5 , indicating that the quality of the studies was high. The authors advised that larger clinical trials of longer duration, particularly by research teams outside of Iran, should be conducted to solidify the benefit of Saffron in MDD (Hausenblas et al., 2013). 
Since that meta-analysis, another small 12-week double-blind RCT $(n=60)$ revealed a significant effect for 50mg of Saffron per day in improving mood and reducing anxiety over placebo (Mazidi et al., 2016). A 6-week double-blind RCT ( $\mathrm{n}=40)$ also showed that Saffron (30 mg per day) was equivalent to the antidepressant fluoxetine in post percutaneous coronary intervention patients with depression (Shahmansouri et al., 2014); while another small $(n=40)$ 4-week double-blind RCT assessing Saffron augmentation (30mg per day) with fluoxetine showed no effect over placebo (Sahraian et al., 2016).

While the weight of this evidence is encouraging, the short study time (four to six weeks), small sample size (30-60 patients), and deficit of Western study sites, limit complete confidence in the results. One caveat in the adopting Saffron into the phytotherapeutic materia medica is that the cost of saffron may be prohibitive, although there is the potential to also use a blend with includes the stigma and the cheaper aerial parts.

\section{Curcuma longa (Turmeric)}

In addition to being employed as a common cooking spice, Turmeric has been used in traditional Ayurvedic and Chinese medicine for centuries to treat a range of health conditions (Kunnumakkara et al., 2017); The main active constituent is regarded as being curcumin (Al-Karawi et al., 2016, Lopresti, 2017), which possesses anti-inflammatory, antioxidant, neuroprotective, and monoaminergic modulatory activities (He et al., 2015, Kunnumakkara et al., 2017). As inflammation is being increasingly regarded as being involved as a causative factor in a subset of 
people suffering from depression (Berk et al., 2013), Turmeric has a potential use as a strong anti-inflammatory (although absorption and bioavailability can be an issue).

A meta-analysis in 2017 by $\mathrm{Ng}$ and colleagues (2017) included six clinical trials (four to eight weeks in duration) involving 377 patients with depression, comparing either Turmeric or curcumin to placebo. Results revealed a significant effect in favour of Turmeric in reducing depressive symptoms. Significant anti-anxiety effects were also reported in three of the clinical trials. Two Turmeric studies are worth further discussion. One 6-week RCT (Yu et al., 2015) involving 108 male adults in China, tested 1000mg of curcumin per day versus placebo as an augmentation to escitalopram. Results showed a significant reduction of depression on the Hamilton Depression Rating Scale (HAM-D) and the Montgomery-Asberg Depression Rating Scale (MADRS) in favour of Turmeric outperforming placebo. Interestingly, the curcumin decreased inflammatory cytokines (Interleukin-1 $\beta$ and Tumour Necrosis Factor- $\alpha$ ) and salivary cortisol concentrations, while increasing plasma brainderived neurotrophic factor (BDNF) levels, compared to placebo. The other study concerns a 4-arm double-blind RCT design to evaluate low-dose curcumin extract (250mg twice per day), a high-dose curcumin extract (500mg twice per day), a combined low-dose curcumin plus saffron extract (15mg twice per day), or placebo, for 12 weeks in 123 participants with MDD (Lopresti and Drummond, 2017). Results revealed that active treatment outperformed placebo in reducing both depression and anxiety scores, with no difference found between the differing doses of curcumin or the curcumin/saffron combination. 


\section{Hypericum perforatum (St John's wort; SJW)}

The flowering tops of SJW has been used traditionally for a variety of nervous system disorders, and has been used over the past decades in certain European countries as a first-line treatment of MDD. The mechanism of SJW's antidepressant action is regarded to involve non-selective inhibition of the neuronal re-uptake of serotonin, dopamine, norepinephrine, Gamma-aminobutyric acid (GABA), and Lglutamate, decreased degradation of neurochemicals, and a sensitisation of and increased binding to various receptors (e.g. GABA, glutamate and adenosine; (Butterweck, 2003, Mennini and Gobbi, 2004, Zanoli, 2004). Human studies have also found that SJW modulates salivary and serum cortisol levels, also having a slight effect on growth hormone levels (Franklin et al., 2006, Schüle et al., 2001). Hyperforin, hypericin and various flavonoids appear to be responsible for the neurochemical modulation (Butterweck, 2003, Laakmann et al., 1998, Zanoli, 2004). As occurs in all herbal medicines, synergy between constituents may be a vital aspect of efficacy (Williamson, 2001), as evidence demonstrates that the absence of rutin, a simple flavonoid constituent in SJW, reduces the antidepressant activity (Wurglics and Schubert-Zsilavecz, 2006). Regardless, there is still controversy, however, regarding the optimum phytochemical standardisation required to exert maximal antidepressant activity, and there are issues with extrapolating preclinical data to humans (as certain SJW constituents do not cross the blood-brain barrier, or display in vitro effects at very high human-equivalent doses) (Cott, 2010). 
A 2008 Cochrane Review meta-analysis of SJW RCTs (Linde et al., 2008) revealed a significant rate of response to treatment from 18 combined studies in favour of SJW versus placebo, and an equivalent effect to selective serotonin reuptake inhibitors (SSRIs). Another meta-analysis conducted around the same time conducted by Rahimi et al. (2009) also revealed a significant for response in favour of SJW over placebo, with a small weighted mean difference between treatments. The comparison with SSRIs showed a non-significant difference between treatments for mean reduction of HAM-D score from baseline.

Due to publicised trial results cf. (Hypericum Depression Trial Study, 2002, Sarris et al., 2012) indicating that SJW was no more effective than placebo (although slightly more effective than sertraline), the herbal medicine is commonly now only recommended for mild to moderate depression, due to clinical concerns of using it in more severe MDD (Clement et al., 2006, Lawvere and Mahoney, 2005, Linde et al., 2005, Shelton et al., 2001). The concerns however may not be well-placed in respect to SJW for treating moderate to severe depression (HAM-D > 20); as it can be noted that a 6-week 2005 RCT $(n=251)$ comparing SJW extract WS 5570 (900 $\mathrm{mg} /$ day) to paroxetine (20 mg/day) and placebo in moderate to severe depression (HAM-D $\geq 22$ ), demonstrated SJW's therapeutic superiority with a 3 point differential reduction on the HAM-D (Szegedi et al., 2005). A similar result was found in terms of $900 \mathrm{mg} /$ day of LI-160 SJW extract being superior to fluoxetine in a 3-arm doubleblind RCT ( $n=135$ ); although it only trended towards significant benefit over placebo (Fava et al., 2005). 
There is also little evidence on the efficacy and safety of SJW in treating adolescents with MDD. Two small open-label trials of SJW were identified where it was trialled in adolescents less than 17 years old (Findling et al., 2003, Simeon et al., 2005). Although the results of these trials were promising, neither had a placebo group or randomisation, and there was a high percentage of drop-outs due to continuing depression or non-compliance. No definitive affirmation of efficacy can be reached from these data.

The safety profile of SJW is very sound, with a systematic review detailing that the degree of adverse effects in 35,562 pooled patients was $0 \%-5.7 \%$, which was comparable to placebo (Knuppel and Linde, 2004). In a 2006 review of 16 postmarketing surveillance studies ( $n=34834$ : Schulz, 2006), SJW was deemed to be 10-fold safer than synthetic antidepressants (adverse effects-0.1\% to $2.4 \%$ ). Apart from rare idiosyncratic reactions, most adverse effects involve reversible dermatological and gastrointestinal effects. Serotonin Syndrome has been documented in case studies (Knuppel and Linde, 2004, Rodriguez-Landa and Contreras, 2003), however, a direct pharmacodynamic interaction has not yet been established. Case studies have detailed possible SJW-induced mania and psychosis (covered later). Overall, as detailed above, SJW has demonstrated equal efficacy to pharmaceutical antidepressants, however it presents with a more favourable side-effect profile.

The main caveat to prescribing SJW is over concerns with potential drug interactions, including a tendency to reduce the serum levels of many 
pharmaceuticals. Current evidence suggests that this is due to hyperforin increasing the expression of the pregnane $X$ receptor, which increases P-glycoprotein expression (the drug efflux pump; Dresser et al., 2003, Izzo, 2004, Moore et al., 2000). It should be noted that low-dose hyperforin preparations (<4mg of hyperforin) may not affect P-glycoprotein expression and hence may be safer (Izzo, 2004, Mueller et al., 2006).

\section{Nepeta menthoides (Catmint) and Cuscuta spp. (Dodder)}

Catmint and Dodder are used in Persian medicine for a range of ailments. Currently there is not clear scientific evidence underpinning any antidepressant activity, however a 4-week Iranian study assessed a freeze-dried aqueous extract of Catmint (800 mg per day) compared with sertraline (100 mg per day) in the treatment of 72 patients with DSM-5 diagnosed MDD (Kolouri et al., 2016). The results revealed a superior effect in the reduction of BDI-II scores in Catmint group compared to sertraline as well as a lower short-term recurrence rate (two weeks post intervention). The adverse events drowsiness, insomnia, decreased libido and constipation were also less frequent in the Catmint group relative to sertraline. Another clinical trial using Catmint (800 mg per day) in combination with Dodder (2000 mg per day) has been conducted in 43 participants with MDD (Firoozabadi et

al., 2015). The 8-week randomised triple-blind controlled clinical trial conducted in Iran, randomly assigned the patients into three groups: Group A (Catmint capsules and conventional drugs), Group B (treated with Dodder capsules and conventional drugs), and Group C (treated only with conventional drugs). Results on the BDI-II 
and the HAM-D showed a superiority of the adjunctive Catmint and Dodder groups compared to medication as usual.

\section{Panax ginseng (Korean ginseng)}

The root of Korean ginseng has been used for millennia across Asia for its perceived 'tonic' and adaptogenic properties, being used particularly in the elderly. Korean ginseng and its active constituents the ginsenosides, have shown potential antidepressant effects in a variety of animal studies and in patients with stress-related somatic symptoms, although the exact mechanisms are currently unknown (Kim et al., 2011). One 8-week prospective open label study, which involved 35 female outpatients who were in remission from a major depressive episode but still experiencing residual symptoms, utilised Korean Red Ginseng at doses of 3 g/day (Jeong et al., 2015). Results revealed that the women reported significant decreases in depressive symptoms on the Depression Residual Symptom Scale (DRSS) and MADRS over the eight-week period. Somatic symptoms measured on the Depression and Somatic Symptom Scale (DSSS) were also attenuated significantly during the study period.

\section{Lavandula spp. (Lavender)}

Lavender has a long traditional use in treating nervous system disorders, in principle due to its bioactive volatile oils (Felter and Lloyd, 2006 (1898)). It is currently unknown as to psychopharmacology underpinning any potential antidepressant activity, however its anxiolytic effects are well-known and this in part is due to the volatile component linalool (Woelk and Schlafke, 2010). An initial small study assessed Lavender's antidepressant activity. The 4-week RCT was

This article is protected by copyright. All rights reserved. 
conducted comparing Lavender tincture (1:5 50\% alcohol, 60 drops) against imipramine, in 45 patients with a HAM-D rating of at least 18 (Akhondzadeh et al., 2003). The results demonstrated that although the herbal extract was less effective than its synthetic counterpart, the combination of both was more effective than imipramine alone, indicating a synergistic effect. A clinical trial involving 80 MDD patients in Iran prescribed $20 \mathrm{mg}$ of citalopram twice a day for eight weeks, with one group being additionally given two cups dried Lavender infusion (5g) compared to no additional treatment (Nikfarjam et al., 2013). After eight weeks, there was a small but significant difference in favour of the Lavender add-on group. The Lavender tea was well tolerated, with no difference in side effects between the groups. A more recent 6-week 3-arm double-blind RCT from the group involving 120 patients tested Lavender augmentation (1500 mg infusion twice daily) with venlafaxine (37.5 mg) versus venlafaxine with placebo (Peppermint infusion twice daily) and control (venlafaxine only) (Nikfarjam et al., 2017). Results revealed that there was no significant difference between adding 'placebo' or Lavender to venlafaxine, with both being effective in reducing depression compared to standard treatment (although it should be noted that the 'placebo' Peppermint also has medicinal properties). High quality supportive research has also been conducted on an oral standardised Lavender oil (Silexan), however this review only focuses on whole Galenical plant extracts.

\section{Rhodiola rosea (Roseroot)}

This article is protected by copyright. All rights reserved. 
One of the most promising herbal medicines in the treatment of depression is Roseroot, a stimulating adaptogen capable of exerting antidepressant activity (Kelly, 2001, Kucinskaite et al., 2004). High pressure liquid chromatography has identified the cinnamyl alcohol betavicianidines, rosavin, rosin, and rosarin as being specific to Roseroot (Bikov et al. 1999, Dubichev et al. 1991, Kurkin and Zapesochnaya 1986). Antidepressant activity of Roseroot has been purported to occur via mono-amine oxidase A modulation (van Diermen et al., 2009), and via modulation of cortisol (Darbinyan et al., 2007, Olsson et al., 2009). A clinical study investigating the influence of Roseroot (370mg and $555 \mathrm{mg}$ doses) on various mental and biological parameters of 161 19-21 year olds, discovered a pronounced antifatigue effect (Shevtsov et al., 2003). This adaptogenic activity in combination with purported monoamine modulation, indicates a novel application in monopolar depression (Stancheva and Mosharrof, 1987, cited by Kelly, 2001).

An initial open label study of 128 depressed patients given $150 \mathrm{mg} 3$ times per day of Roseroot or placebo, showed that two-thirds of those taking Roseroot had a significantly improved mood (Brichenko and Skorokhova 1987, Saratikov and Krasnov 1987a, 1987b). A double-blind RCT of a standardised extract of Roseroot $\left(\mathrm{SHR}-5^{\circledR}\right)$ as a monotherapy for 89 adults who met DSM $4^{\text {th }}$ Edition, Revised (DSMIV-TR 2000) criteria for mild to moderate depression, found that those given 340 $\mathrm{mg} /$ day or $680 \mathrm{mg} /$ day of the extract for six weeks showed significantly greater improvements in mean HAM-D compared to the placebo group (Darbinyan et al. 2007). A more recent study of a standardised Roseroot extract in MDD, sought to determine whether it was more effective than sertraline and placebo, in a 12-week 
double-blind RCT (Mao et al., 2015). A total of 57 participants were recruited, with results revealing a non-significant difference between treatments for depression and anxiety outcomes. The reduction of depression and anxiety did however favour the antidepressant, although the side effects were far less pronounced in the Roseroot group compared to the sertraline.

\section{Dysthymic disorder (DD)}

Dysthymic disorder is characterised in the DSM-5 as a persistent low mood (although not meeting the criteria of MDD) occurring for at least 2 years on more days than not (APA, 2013). Only one study was located assessing the herbal treatment of dysthymia. A 2006 double-blind RCT $(n=150)$ using a standardised SJW extract PM235 (810 mg/day) observed that while significant improvement occurred in non-dysthymic depressed patients, no statistical improvement was discovered in ICD-10 depressed dysthymic patients as assessed via HAM-D, a visual analogue scale (VAS) and the Beck Depression Inventory (BDI) (Randløv et al., 2006). As discussed in Randlov et al. (2006) it is possible that herbal interventions may not succeed in ameliorating persistent dysthymic mood, as this may be a reflection of an established melancholic personality trait in certain people.

\section{Seasonal affective disorder (SAD)}

Controversy exists regarding the exact diagnostic classification of seasonally provoked mood disorders (Magnusson and Partonen, 2005), with SAD being the term commonly adopted (APA, 2013). To date, three trials have been performed using herbal agents in SAD. Two open-label trials using SJW alone (300 mg thrice 
daily) and SJW plus light therapy found there was a significant reduction of winterprovoked depression, although there was no statistical difference between the two treatments (Martinez et al., 1994, Wheatley, 1999). A more rigorous small-sample doubled-blind RCT using a twice daily dose of the Ginkgo extract PN 246 (containing $24 \mathrm{mg}$ flavone glycosides and $6 \mathrm{mg}$ terpene lactones) to prevent the onset of SAD in 27 people, found no difference between the active and placebo group on the MADRS and VAS outcomes (Lingærde et al., 1999). Currently, there is no supportive evidence available for any specific herbal intervention to confidently treat SAD, and light therapy is the often regarded as a first-line intervention (Gordijn et al., 2012).

\section{Depression with anxious symptoms (AnxD)}

While no diagnosis of AnxD is identified in the DSM-5, anxiety symptoms are endemic in depression, and the ICD-10 regards this as 'Mixed Anxiety and Depression (Kessler et al., 2003, Sheehan et al., 1998). Further, true comorbidity of depressive and anxious conditions commonly occurs (Hunt et al., 2004, Sartorius et al., 1996). In cases where there is a combination of depression and anxiety, adjunctive anxiolytic medications with antidepressants, have been suggested as a strategy to address acute anxiety, as the thymoleptic effect of antidepressant medications often take two to three weeks to occur (Baghai et al., 2006, Nemeroff, 2003). Two studies were located: an open, practice-orientated study using SJW alongside low or high dose Valeriana officinalis (Valerian) extract to treat AnxD demonstrated marked success, with results tending to suggest more effectiveness in the higher dose Valerian group (although this was not confirmed statistically) 
(Müller et al., 2003). A 2009 double-blind cross-over RCT involving 28 adults with MDD and co-occurring anxiety were given a combination of SJW (1.8gm $3 \times$ day; 2970mg of hypericin) and Kava (2.66 gm 3 x day; 150mg of kavalactones) after a placebo run-in of two weeks (Sarris et al., 2009b). Results assessing the effects of the herbal combination in the two controlled phases, each of four weeks found no significant Group x Time interaction for any depression or anxiety outcome.

\section{ANXIETY DISORDERS}

\section{Generalized anxiety disorder (GAD) and non-specified anxiety}

GAD is diagnosed in persons with excessive worry and anxiety, accompanied by more than three somatic symptoms (e.g. tension, irritability) which occurs more days than not, for a period of at least 6 months (APA, 2013). Anxiety represents the broadest area of research of herbal medicines in psychiatric disorders, with the most individual phytomedicines possessing documented anxiolytic activity (Sarris et al., 2013a, Sarris et al., 2013b). Kava is the herbal medicine that has been the most extensively researched anxiolytic, albeit with previous concerns existing regarding its safety due to cases of hepatotoxicity.

\section{Bacopa monniera (Brahmi)}

Although Brahmi is usually studied for its reputed cognitive enhancing activity, the plant has traditional use in treating anxiety and insomnia, and even has been

This article is protected by copyright. All rights reserved. 
recommended in years past for the antiquated diagnosis of 'insanity'. Preclinical research has demonstrated various CNS actions including nootropic, antidepressant, anxiolytic, and antioxidant effects. Neurologically-focused preclinical studies have shown that Brahmi modulates acetylcholine, dopamine, serotonin, and noradrenalin pathways (Charles et al., 2010), and increases protein kinase activity within the hippocampus (Singh and Dhawan, 1997). The key chemical constituent is regarded as bacoside A. One study was located assessing Brahmi effect on anxiety, the 2001 double-blind RCT using $300 \mathrm{mg}$ of Brahmi demonstrating a marked reduction of state anxiety compared with placebo after 12 weeks of treatment (Stough et al., 2001).

\section{Centella asiatica (Gotu Kola)}

Gotu kola has been used for centuries in Ayurvedic and traditional Pan-Pacific medicine for a variety of therapeutic applications, including treatment of anxious and depressive complaints. Gotu kola (and the key constituents) have displayed GABAergic effects revealed in studies analysing GABA-transaminase (GABA-T) and glutamic acid decarboxylase activity (Awad et al. (2007a). A double-blind, placebo-controlled study was undertaken to evaluate the anxiolytic activity of Gotu kola via the acoustic startle response (ASR) in 40 healthy participants (Bradwejn et al., 2000). Participants were randomly assigned to receive either a large single $12 \mathrm{~g}$ orally administered dose of Gotu kola or placebo. Compared with placebo, Gotu kola significantly attenuated the peak ASR amplitude 30 and 60 min after treatment, thereby indicating anxiolytic activity. Currently no robust RCTs exist, however an open label study of $500 \mathrm{mg}$ of Gotu kola twice daily for two months in 33 patients 
with GAD (Jana et al., 2010), revealed significant improvements in anxiety following 60 days of treatment on the Hamilton Anxiety Rating Scale (HAM-A), along with significant reductions in secondary measures of stress and depression.

\section{Galphimia glauca (Galphimia)}

In traditional Mexican and Central American cultures, the leaves and stem from Galphimia are used for nervous disorders, with the serotonergic galphimine B being regarded as an active constituent (Jimenez-Ferrer et al., 2011). It has been shown to interact with serotonergic transmission via the dorsal hippocampus in rats, by increasing the frequency of neuronal discharge in CA1 cells, activating the $5 \mathrm{HT}(1 \mathrm{~A})$ receptors (Jimenez-Ferrer et al., 2011). In a 4-week double-blind RCT, an aqueous extract of Galphimia was administered to 153 patients with a DSM-IV diagnosis of GAD (Herrera-Arellano et al., 2007). The positive control group received $1 \mathrm{mg}$ of lorazepam in capsule form twice daily versus the Galphimia group receiving $310 \mathrm{mg}$ of the extract twice daily. Results revealed no significant difference between groups in the anxiolytic effect found across time. No significant side-effects were noted in the Galphimia group, whereas $21 \%$ of people in the lorazepam group experienced excessive sedation. In a follow-up study (Herrera-Arellano et al., 2012) 191 patients with a DSM-IV diagnosis of GAD were administered $3.48 \mathrm{~g}$ of dried Galphimia per capsule (0.35 $\mathrm{mg}$ or $0.7 \mathrm{mg} /$ day of galphimine $\mathrm{B}$ ), versus $1 \mathrm{mg}$ to $2 \mathrm{mg}$ of lorazepam over a 15-week period. A significantly greater reduction in HAM-A score occurred for Galphimia treatment in comparison to lorazepam over the course of the clinical trial.

This article is protected by copyright. All rights reserved. 


\section{Matricaria recutita (Chamomile)}

The flowering tops of Chamomile is widely consumed throughout the Western world in tea form, with a history of traditional use as a mild relaxant (Amsterdam et al., 2009a). Preclinical research has revealed a range of effects considered to be mediated via modulation of the GABA system (Avallone et al., 2000, Awad et al., 2007b). One of the active constituents is the flavone apigenin, which is a benzodiazepine receptor ligand with anxiolytic activity (Salgueiro et al., 1997, Viola et al., 1995). An 8-week double-blind RCT involving 57 GAD patients showed significantly greater reductions in anxiety from Chamomile (220mg, one to four times daily) on the HAM-A scale in compared to the placebo group (Amsterdam et al., 2009b). A post-hoc analysis of the same sample found that Chamomile may also reduce co-morbid depression (HAM-D rated) in anxious patients (Amsterdam et al., 2012).

Two further clinical trials reported both short and long term (i.e. 8 and 38weeks) effects of anxiety treatment using 1500mg of Chamomile (500mg capsule 3 times daily) in 179 patients with GAD. At week 8, 58\% of patients met the criteria for clinical response in the Chamomile group, with significant reductions in mean anxiety (GAD-7) across the entire sample (Keefe et al., 2016). For the long-term study, clinical responders were randomly assigned to continued active or placebo treatment for a further 26 weeks. GAD relapse rates were $25.5 \%$ in the placebo group, and only $15.2 \%$ in the continued treatment group (Mao et al., 2016). Although neither the difference in relapse rates, nor 
the HAM-A or the Beck Anxiety Inventory (BAI) symptom reductions, reached statistical significance.

\section{Melissa officinalis (Lemon balm)}

Lemon balm has traditional usage as a mild sedative and spasmolytic agent. In-vitro studies have revealed anxiolytic activity via elevation of GABA levels from inhibition of GABA-T (Awad et al., 2007a, Awad et al., 2009). A double-blind RCT was conducted with 20 participants who were given single doses of 300, 600 and 900 mg of Lemon balm or a matching placebo at 7-day intervals. Self-rated calmness, as assessed by Bond-Lader mood scales was elevated at the earliest time points by the lowest dose, whilst perceived alertness was significantly reduced at all time points following the highest dose (Kennedy et al., 2002). A double-blind cross-over RCT ( $n=18)$ using two separate single doses of Lemon balm extract (300 mg, 600 mg) and placebo (Kennedy et al., 2004), determined that acute dosing of Lemon balm demonstrated a significant increase in self-rated calmness and reduced alertness in subjects via a defined intensity stressor simulation (DISS) test. A later study of a similar design tested a Lemon balm and Valerian extract combination (600, 1200 or $1800 \mathrm{mg}$ pills consisting of three parts Valerian extract to two parts Lemon Balm) against placebo in 24 healthy volunteers at three time points (1,3 and 6 hours post-test) (Kennedy et al., 2006). The results demonstrated that although none of the Bond-Lader scores were significantly different between groups, the lowest dose of the combination ameliorated the anxiogenic effects of the DISS after 3 and 6 hours, while the higher doses failed to outperform placebo (with the 1800 mg dose in fact causing increased 'state' anxiety after 1 hour. 
A combined Lemon balm leaf (320mg per day) and Valerian root $(640 \mathrm{mg})$ preparation was investigated in a large sample 4-week open, multi-centre study in children less than 12 years $(n=918)$ suffering from restlessness and nervous dyskoimesis (Muller and Klement, 2006). The primary symptoms of dyssomnia and restlessness were reduced from 'moderate/severe' to 'mild' or 'absent' in most of the children, with $70.4 \%$ of the patients with restlessness improving. Both parents and investigators assessed efficacy as 'very good' or 'good' $(60.5 \%$ and $67.7 \%$, respectively).

\section{Passiflora incarnata (Passionflower)}

Passionflower has been used in traditional medicine in the Americas to allay restlessness and overcome wakefulness, when these are the result of exhaustion or the nervous excitement of debility' (Felter and Lloyd, 2006 (1898)). The principle constituents include alkaloids such as chrysin, flavonoids, and phenolic compounds (Wohlmuth et al., 2010). GABAergic modulation has been posited as occurring via a number of neurochemical pathways: GABA-a and GABA-b receptor subtypes and GABA reuptake inhibition, and modulation of the GABA-a receptor complex through benzodiazepine sites (Appel et al., 2011, Nassiri-Asl et al., 2008). An initial Iranian RCT using Passionflower extract in a sample of participants with GAD $(n=36)$ showed that the plant was as effective (with less side effects) as oxazepam (30 mg/day) in reducing anxiety (Akhondzadeh et al., 2001). Since then, six studies involving human populations were found; four examined effects on pre-operative anxiety via RCT designs (Aslanargun et al., 2012, Dantas et al., 2017, Kaviani et al., 2013, Movafegh et al., 2008), all reporting significant benefits from 
Passionflower in comparison to placebo and non-inferiority to pharmaceutical comparators.

Most recently, this effect was observed in a double-blind RCT of 40 dental surgery patients (Dantas et al., 2017), showing Passionflower (260mg) orally administered 30 minutes before dental surgery reduced subjective anxiety along with physiological indicators (i.e. blood pressure, heart rate). This occurred to the same extent as midazolam, however with fewer cognitively-impairing side effects. It is worth noting also that Citrus aurantium (Orange blossom) in 60 patients undergoing minor operation also was found in a double-blind RCT to significantly reduce preoperative anxiety compared to a saline placebo (Akhlaghi et al., 2011).

\section{Piper methysticum (Kava)}

The South Pacific medicinal plant Kava has traditional uses as a relaxant (and an inebriant at higher doses), and is used in modern phytotherapy as a treatment for anxiety. Kava's mechanisms of action are considered to involve interaction of the active constituents, the kavalactones, with GABA voltage-gated sodium ion channels, enhanced ligand binding across GABA-a receptor subtypes, and reduced excitatory neurotransmitter release via blockade of calcium ion channels (Magura et al., 1997)(He et al., 1997, Mathews et al., 2005).

A 2003 Cochrane Review of double-blind RCTs using Kava mono-preparations (60-280 mg of kavalactones) in a variety of anxiety conditions, included 12 trials that met the inclusion criteria (Pittler and Ernst, 2003). Results of the review 
documented a statistically significant anxiolytic activity compared with placebo in all but one trial, demonstrating that Kava is an effective short-term treatment of anxiety. Meta-analysis of seven homogenous trials using HAM-A as the primary outcome, found that Kava reduced anxiety significantly over placebo. Subsequent short-term double-blind RCTs using water-soluble rootstock noble Kava cultivar extracts (between 120-240mg of kavalactones per day) have also further confirmed these findings (Sarris et al., 2009a, Sarris et al., 2013c) in chronic generalised anxiety and GAD.

An insufficiency of trials exist studying the efficacy of Kava compared with synthetic agents such as benzodiazepines or antidepressants. One study assessed Kava in comparison with buspirone or opipramol in treating GAD using an 8-week $(n=129)$ double-blind RCT design (Boerner et al., 2003). The results of the study found no significant difference between Kava and buspirone or opipramol regarding all efficacy and safety measures. Seventy five percent of patients were classified as responders (50\% reduction of HAM-A score) in each treatment group, with $60 \%$ achieving full remission.

Concerns of hepatotoxicity have emerged in recent years prompting postmarketing, clinical and toxicology studies to be performed to assess the safety of Kava. A 2002 review of Kava was conducted to assess the plant's safety profile via literature searches of four electronic databases, papers' reference lists, spontaneous reporting schemes of the WHO and national drug safety bodies and ten manufacturers of Kava preparations (Stevinson et al., 2002). The data suggests 
that adverse events are in general very rare, mild, and usually reversible. Since this review, over the past 15 years there have been no obvious further human liver toxicity associations come to light in the literature. Previous liver issues found with German Kava products may be due in part to the use of aerial parts and root and stem peelings, and poorly prepared raw material (Teschke et al., 2011a). The WHO commissioned a report assessing the risk of Kava products (Coulter, 2007). Recommendation 2.1.3 from this report suggested that products from water-based suspensions be developed and tested in clinical trials and that these preparations be used preferentially over acetonic and ethanolic extracts. Thus the use of standardised formulations of Kava using peeled rootstock extracts of a noble cultivar (such cultivars are higher in kawain and dihydrokavain, and lower in dihydromethysticin) is recommended. For further discussion on this cf. (Teschke et al., 2011a, Teschke et al., 2011b).

\section{Scutellaria lateriflora (Scullcap)}

Scullcap is a plant medicine that has traditional use as a sedative in various nervous system disorders in Native American and Eclectic medicine. Preclinical models have identified the compounds baicalin and baicalein purported to be involved its anxiolytic activity via binding to the benzodiazepine site of $\operatorname{GABA}(A)$ (Awad et al., 2003). Two human studies using Scullcap extract were found, both in non-clinical samples. In a double-blind crossover RCT $(n=43)$ in which participants were initially randomised into either two weeks of 350mg of Scullcap extract (three times per day) or a placebo comparator, Brock et al. (2014) reported no difference in anxiety outcomes between groups. This was ascribed to both a 'floor effect', as 
these healthy volunteers were mostly non-anxious at baseline, as well as baseline heterogeneity between groups. An older poorly reported double-blind cross-over RCT of healthy adults ( $n=19)$ suggested Scullcap may reduce symptoms of anxiety and tension after acute administration compared with control, although this was determined without significance testing (Wolfson and Hoffmann, 2003).

\section{Ginkgo biloba (Ginkgo)}

Although Ginkgo is used therapeutically to treat cognitive decline, peripheral arterial disease, and tinnitus, studies have noted that mood modulation can occur in cognitively impaired subjects (Fehske et al., 2009). The anxiolytic effects of Ginkgo extract and its four terpenoid components (ginkgolide-A, ginkgolide-B, ginkgolide-C, and bilobalide) were have an anxiolytic effect in animal models (Kuribara et al., 2003). A 2006 double-blind RCT ( $n=107)$ was conducted using EGb 761 extract (480 mg or $240 \mathrm{mg}$ per day) or placebo for four weeks in adults with GAD or adjustment disorder with anxious mood, as assessed via DSM-III-R (Woelk et al., 2007). Results showed that the participants' HAM-A total scores decreased significantly in both the $480 \mathrm{mg}$ per day and 240mg per day Ginkgo groups, relative to placebo, in a dose-dependant manner.

\section{Rhodiola rosea (Roseroot)}

While Roseroot is commonly studied for its anti-fatigue and mood-elevating effects (as detailed above), two studies are available for review in the area of anxiety. A 2week clinical trial involved 80 mildly anxious patients who were given either $2 \times 200$ mg per day of Roseroot (Vitano) or a non-placebo control condition (no treatment) 
(Cropley et al., 2015). Results showed that relative to the control, the Roseroot group demonstrated a significant reduction in self-reported, anxiety, stress, anger, confusion and depression and improvements in total mood. Caution needs to be extended to this finding due to the lack of a credible control. Roseroot (SHR-5) has also been studied in a small pilot 10-week open-label design $(n=10)$ in participants with a GAD (Bystritsky et al., 2008). Results revealed that mean HAM-A scores were significantly different at the end of treatment compared to baseline, with five out of ten participants regarded as responders to treatment. As this study was uncontrolled, conclusions as to its efficacy need to be tempered.

\section{Withania somnifera (Ashwagandha)}

Classified in Ayurvedic medicine as a 'rasayana', a medicine used to enhance physical and mental performance and ward off disease, Ashwagandha has been adopted into Western herbal material medica for its use in nervous system and endocrine disorders. An animal study has observed adaptogenic effects of Ashwagandha via a stress-inducing procedure, revealing attenuation of stressrelated parameters (cortisol levels, mental depression, sexual dysfunction) (Bhattacharya and Muruganandam, 2003). The purported active constituents are considered to be the withanolides, which have been shown to possess GABAmimetic properties (Andrade, 2009, Bhattacharya et al., 2000).

In human studies, a recent systematic review by Pratte et al. (2014) discussed previous studies of Ashwagandha on anxiety/stress outcomes. They identified five human RCTs with a total of 400 participants. All five trials reported at least one 
significant benefit of the herbal medicine in comparison to control conditions for anxiety and/or stress related outcomes. The doses of the herbal medicine ranged from $125 \mathrm{mg}$ to $1200 \mathrm{mg}$ per day, with trials being between six to 16 weeks. Since this review, one further eligible study has been conducted; a double-blind RCT in 52 people with chronic stress, comparing 600mg of Ashwagandha extract per-day to placebo over 8 weeks (Choudhary et al., 2017). Results revealed significantly greater reductions in stress outcomes from the plant medicine, corresponding with significant decreases in salivary cortisol (a stress/anxiety biomarker).

\section{Social Phobia}

Social anxiety disorder (social phobia) is characterised by persistent fear of social or performance situations in which marked stress and or embarrassment occurs (APA, 2013). There is avoidance of these situations and significant interference with the social functioning. Herbal medicine in the treatment of social phobia has been documented (Boerner, 2001). A case study of a 37 year old female patient suffering from GAD and both simple and social phobias achieved nearly complete remission after 6 months of treatment with three tablets of LI 150 Kava extract (equivalent to $135 \mathrm{mg}$ of kavalactones per day). In this updated review, only one clinical study trialling a plant medicine in social phobia was still found. A double-blind RCT using SJW (flexible-dose 600-1800 mg daily) in 20 people with social phobia (as assessed via the Liebowitz Social Anxiety Scale), revealed no significant differential impact over placebo, although a trend towards improvement was demonstrated (Kobak et al., 2005b). 


\section{Obsessive-Compulsive Disorder (OCD)}

The primary features of OCD are unreasonable recurrent obsessions or compulsions that are sufficiently severe to consume time and cause marked distress (APA, 2013). A small sample 12-week open-label exploratory study was conducted evaluating SJW (450 mg 0.3\% hypericin 2/day) in the treatment of OCD patients $(n=12)$ (Taylor and Kobak, 2000). The results demonstrated a significant change of 7.4 points on the Yale-Brown Obsessive Compulsive Scale (Y-BOCS) after 12 weeks, with five patients (42\%) being rated 'much' or 'very much improved', six (50\%) were 'minimally improved', and one (8\%) had 'no change' on the clinicianrated CGI. A later study sought to validate these results in a 12-week double-blind RCT (Kobak et al., 2005a). SJW (LI 160) at a flexible dose of 600-1800 mg/day or placebo was administered to 60 adults with OCD. SJW did not ameliorate OCD on the Y-BOCS (3.43) in comparison with placebo (3.60), or differentially affect clinician rating.

A double-blind RCT using Silybum marianum (Milk Thistle), a traditional Mediterranean and Persian plant, was conducted by Iranian researchers to assess its effects on OCD (Sayyah et al., 2010a). The putative anti-OCD effects of Milk Thistle may be attributable to the flavanoid complex silymarin (silibinin a key constituent), which in preclinical studies has been found to increase serotonin levels in the cortex (Osuchowski et al., 2004), and ameliorate decreases in dopamine and serotonin in the prefrontal cortex and hippocampus associated with methamphetamine abuse (Lu et al., 2010). The study involved 35 participants with a Y-BOCS score of $>21$ who were randomly assigned $200 \mathrm{mg}$ of Milk Thistle leaf 
extract (standardisation and chemical profile not detailed by researchers) or $10 \mathrm{mg}$ of fluoxetine three times daily for eight weeks (Sayyah et al., 2010b). Results revealed no significant difference between treatments from baseline to week 8 . An 8-week double-blind RCT using a Valerian (765 mg per day) among 31 adults with OCD (DSM-IV diagnosed) also found that the extract significantly reduced symptoms of the disorder (Pakseresht et al., 2011).

\section{Somatoform Disorders}

The essential feature of somatoform disorders is the presence of physical (somatic) symptoms that cause clinically significant distress or social/occupational impediment that are not explained by a general medical condition or substance (APA, 2013). The diagnosis of somatoform disorders is problematic, as it is difficult to distinguish between a subjective rating that is not open to direct observation, and it is difficult to distinguish between a psychosomatic and a purely physical presentation (Bradfield, 2006, Kroenke and Rosmalen, 2006, Lecrubier, 2006).

Three double-blind RCTs treating somatoform disorders were located. A 6-week multi-centre RCT ( $\mathrm{n}=151)$ found that SJW extract (600 mg/day) was significantly superior to placebo in reducing somatoform symptoms as assessed via HAMASOM scale (Volz et al., 2002). A later double-blind RCT $(n=184)$ tested SJW extract in patients with somatization disorders. The results using six outcome measures, demonstrated that $45.4 \%$ of the SJW group were classified as responders, compared with $20.9 \%$ who took placebo (Muller et al., 2004). 
A short-term two-week study evaluated tablets containing 90mg of Petasites hybridus (Butterbur) in combination with Ze185: Valerian 90mg, Passionflower 90mg, Lemon balm 90mg in patients with somatoform disorders (Melzer et al., 2009). A total of 182 patients were randomised for a 3-arm trial: Ze185 and Butterbur versus Ze185 versus placebo. The four-herb combination was found to be significantly superior to the 3-combination and placebo on a VAS and the BDI-II. All herbal combinations were found to be well-tolerated, with no serious adverse events.

\section{Attention-Deficit Hyperactivity Disorder (ADHD)}

ADHD is diagnosed by the DSM- $V$ as a presentation at clinical levels of hyperactivity, impulsivity and cognitive dysfunction related to inattention and impulsivity, occurring before the age of 12; these symptoms must be persistent and still be sufficient to cause significant personal and social distress (APA, 2013). An open label trial of American ginseng (Panax quinquefolium) plus $100 \mathrm{mg} /$ day of Ginkgo in 36 children with ADHD given $400 \mathrm{mg} /$ day for four weeks found that $74 \%$ improved significantly on Conner's ADHD scale, while having a $44 \%$ improved on a social problems measure (Lyon et al. 2001).

Pycnogenol (an extract from French maritime pine bark) was also found to be superior to placebo after four weeks in a double-blind RCT involving 61 children with ADHD. On standardised measures and teacher and parent ratings, students on Pycnogenol had significantly greater improvements in hyperactivity, attention, 
concentration, and visual-motor coordination (Trebatická et al. 2006). The mechanisms of action for both Pycnogenol and Ginkgo are considered to in part to be mediated via antioxidant activity. In respect to non-supportive data, a doubleblind RCT by Salehi and colleagues (2009) found that Ginkgo (80-120mg/day) had no comparable benefit to methylphenidate in 50 children with ADHD. (Salehi et al., 2010) While a high-profile robust 8-week double-blind RCT using 900mg/day of SJW also found no benefits in the treatment of ADHD. (Weber et al., 2008).

\section{Bipolar disorder I/II (BD)}

Bipolar II disorder is characterised in the DSM-V as a condition whereby periods of MDD are accompanied by one or more hypomanic episodes, while in contrast, bipolar disorder I is diagnosed by the occurrence of one or more full-blown manic episodes with or without MDD (APA, 2013). Although herbal intervention in bipolar conditions may have a therapeutic role, it is currently recommended that these are studied and prescribed only as an adjunctive therapy with mood stabilisers in cases of pronounced mood oscillation (Currier and Trenton, 2002, Mohr et al., 2005).

It should be firstly noted that cases of herbal medicine-induced mania have been documented with SJW (Fahmi et al., 2002, Guzelcan et al., 2001, Nierenberg et al., 1999, Stevinson and Ernst, 2004), Ma Huang (Ephedra sinica) (Boerth and Caley, 2003, Maglione et al., 2005), Ginkgo (Spinella and Eaton, 2002) and Ginseng (type not specified) (Vazquez and Aguera-Ortiz, 2002). High-dose SJW or concomitant pharmaceutical or recreational drugs were involved in most cases. Furthermore, causal links could not be established in these cases due to a lack of re-challenge 
with the herbal medicine involved. Although herbal-induced mania appears to occur idiosyncratically, monitoring is advised in cases of high-dosage, with use in patients with known bipolar disorders.

To date one study has been conducted using a plant medicine for bipolar disorder; a clinical trial using Ashwagandha. Sixty euthymic subjects with DSM-IV bipolar disorder were enrolled in an 8-week, double-blind RCT of Ashwagandha (500 mg/day) as a 'pro-cognitive' agent added adjunctively to the medications being used as maintenance treatment for bipolar disorder (Chengappa et al., 2013). Cognitive testing at baseline and 8 weeks was assessed as the primary efficacy outcome. On the secondary outcomes of mood and anxiety scales, no significant difference between groups was found (however it should be noted that participants were euthymic at the commencement of the study). Compared to placebo, Ashwagandha provided significant benefits for three cognitive tasks: digit span backward, Flanker neutral response time, and the social cognition response rating of the Penn Emotional Acuity Test.

\section{Schizophrenia}

Schizophrenia and related psychoses, are serious mental disorders with a profound impact on cognition, emotion and behaviour, and include symptoms such as hallucinations, thought disorder and delusions (APA, 2013). Adjuvant prescription of Ginkgo to antipsychotics in chronic schizophrenia treatment was evaluated via meta-analysis. A total of eight double-blind RCTs involving 1033 patients were assessed (Chen et al., 2015). The result showed that Ginkgo had a significant 
difference in ameliorating total and negative symptoms of chronic schizophrenia as an adjuvant therapy to antipsychotics, this is potentially due to the antioxidant effects. No significant between-group adverse effects were revealed, however a reduction of extrapyramidal side effects was not evident across the Ginkgo cohort. The authors note that all of these eight trials were carried out in China, and further transcultural research is needed.

A proprietary standardised American ginseng extract (HT1001) was assessed in a 4-week double-blind RCT involving 64 individuals with DSM-IV diagnosed schizophrenia (Chen and Hui, 2012). The primary outcome was assessment of cognitive effects. Results revealed that visual working memory was significantly improved in the American Ginseng group, but not in the placebo group. Furthermore, extrapyramidal symptoms were significantly reduced after four weeks treatment, compared to the placebo group. The mechanism of action underpinning these effects are currently not entirely known, however anxiolytic effects have been revealed in animal models (Wei et al., 2007).

\section{DISCUSSION}

The current updated review, revealed 24 herbal medicines for 11 psychiatric conditions, however unlike the previous review which only uncovered a highstandard of evidence existing for Kava and SJW, further research has been conducted over the past decade giving weight to the use of Saffron for depression and Passionflower for anxiety. Other herbal medicines found to have encouraging 
evidence in the previous review, and advised for further research were Roseroot, Scullcap, and Zizyphus jujuba (Sour date seed). While the first two have a couple of additional positive small-scale studies for depression and anxiety, respectively, larger studies are still required, and to date no double-blind RCTs have been conducted involving Sour date seed. Recently studied plant medicines such as Galphimia, Tumeric, and Ashwagandha also provide very encouraging evidence as additional therapeutic options for depressive and anxiety disorders, and inspire the pursuit of researching more plant medicines with traditional usage for mental health conditions. While MDD and GAD are still commonly researched in this field, study of herbal medicines in psychotic disorders, OCD, and ADHD has only grown marginally in the past decade. There is still a paucity of research in phobic, somatoform disorders, and currently none for panic disorder.

Outside of some European and Asian healthcare models, integration of psychotropic herbal medicines into conventional medical practice appears to still be some way off. In the past decade, no substantial advance has occurred in the development of new classes of synthetic antidepressant and anxiolytic medications, with SSRIs and benzodiazepines currently remaining first-line treatments in depression and anxiety disorders, respectively. However as in the case of depression, a significant percentage of patients do not experience full remission with pharmaceutical treatments additional treatment options are still needed. One potential option that is relatively unexplored, is in the adjunctive co-prescribing of herbal medicines in combination with pharmaceuticals. In some herbal medicines it is recognised that co-prescription may be unwise, for example SJW with SSRIs due 
to potential serotonin syndrome, and Kava in combination with benzodiazepines due to a theoretical additive sedative effect. Regardless, co-prescription of certain herbal medicines with pharmaceuticals with complementary pharmacodynamic actions may in fact provide a beneficial synergistic effect (Borgert et al., 2005, Williamson, 2001). This also potentially allows for a lower dose of synthetic pharmaceuticals to be taken, thus reducing potential side effects. Regardless of this potential application, to date little study has occurred, aside from some isolated studies exploring augmentation of antidepressants. This remains an area of potential future study.

In conclusion, while evidence has grown in the past decade, there is still a need to conduct further robust double-blind RCTs for several herbal medicines with encouraging pilot data. There is also immense scope to explore different combinations of these, enhanced standardised preparations of these herbal medicines, and the application in a wider range of psychiatric disorders.

This article is protected by copyright. All rights reserved. 


\section{Conflicts of interest}

JS has received either presentation honoraria, travel support, clinical trial grants, book royalties, or independent consultancy payments from: Integria Healthcare \& MediHerb, Pfizer, Scius Health, Key Pharmaceuticals, Taki Mai, Bioceuticals \& Blackmores, SohoFlordis, Healthworld, HealthEd, HealthMasters, Elsevier, Chaminade University, International Society for Affective Disorders, Complementary Medicines Australia, Terry White Chemists, ANS, Society for Medicinal Plant and Natural Product Research, SanofiAventis, Omega-3 Centre, the National Health and Medical Research Council, CR Roper Fellowship

\section{Acknowledgements}

The author of the paper gratefully acknowledges the assistance with the manuscript preparation and gathering of data by Diana Karamacoska, proofing and editing by Lachlan Cribb; and the original significant contributions of Professor David Kavanagh in proofing and structuring the 2007 review.

This article is protected by copyright. All rights reserved. 


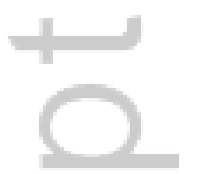

This article is protected by copyright. All rights reserved. 


\section{References}

Akhlaghi, M., Shabanian, G., Rafieian-Kopaei, M., Parvin, N., Saadat, M. and Akhlaghi, M. 2011. Citrus aurantium blossom and preoperative anxiety. Revista brasileira de anestesiologia, 61: 702-12.

Akhondzadeh, S., Kashani, L., Fotouhi, A. et al. 2003. Comparison of Lavandula angustifolia Mill. tincture and imipramine in the treatment of mild to moderate depression: a double-blind, randomized trial. Progress in neuro-psychopharmacology \& biological psychiatry. pp. 123-127.

Akhondzadeh, S., Naghavi, H. R., Vazirian, M., Shayeganpour, A., Rashidi, H. and Khani, M. 2001. Passionflower in the treatment of generalized anxiety: a pilot double-blind randomized controlled trial with oxazepam. Journal of Clinical Pharmacy and Therapeutics, 26: 363-367.

Al-Karawi, D., Al Mamoori, D. A. and Tayyar, Y. 2016. The Role of Curcumin Administration in Patients with Major Depressive Disorder: Mini Meta-Analysis of Clinical Trials. Phytother Res, 30: 175-83.

Altman, D. G., Schulz, K. F., Moher, D. and Et Al. 2001. The revised consort statement for reporting randomized trials: Explanation and elaboration. Annals of Internal Medicine, 134: 663-694.

Amsterdam, J. D., Li, Y., Soeller, I., Rockwell, K., Mao, J. J. and Shults, J. 2009a. A Randomized, Double-Blind, Placebo-Controlled Trial of Oral Matricaria recutita (Chamomile) Extract Therapy for Generalized Anxiety Disorder. Journal of Clinical Psychopharmacology, 29: 378-382 10.1097/JCP.0b013e3181ac935c.

Amsterdam, J. D., Li, Y., Soeller, I., Rockwell, K., Mao, J. J. and Shults, J. 2009b. A randomized, double-blind, placebo-controlled trial of oral Matricaria recutita (chamomile) extract therapy for generalized anxiety disorder. J Clin Psychopharmacol, 29: 378-82.

Amsterdam, J. D., Shults, J., Soeller, I., Mao, J. J., Rockwell, K. and Newberg, A. B. 2012. Chamomile (Matricaria recutita) May Have Antidepressant Activity in Anxious Depressed Humans - An Exploratory Study. Alternative therapies in health and medicine, 18: 44-49.

Andrade, C. 2009. Ashwagandha for anxiety disorders. The world journal of biological psychiatry : the official journal of the World Federation of Societies of Biological Psychiatry, 10: 686-7.

Apa. 2013. Diagnostic and statistical manual of mental disorders (5th edition), Washington D.C.

Appel, K., Rose, T., Fiebich, B., Kammler, T., Hoffmann, C. and Weiss, G. 2011. Modulation of the gammaaminobutyric acid (GABA) system by Passiflora incarnata L. Phytother Res, 25: 838-43.

Aslanargun, P., Cuvas, O., Dikmen, B., Aslan, E. and Yuksel, M. U. 2012. Passiflora incarnata Linneaus as an anxiolytic before spinal anesthesia. Journal of anesthesia, 26: 39-44.

Avallone, R., Zanoli, P., Puia, G., Kleinschnitz, M., Schreier, P. and Baraldi, M. 2000. Pharmacological profile of apigenin, a flavonoid isolated from Matricaria chamomilla. Biochemical Pharmacology, 59: 13871394.

Awad, R., Arnason, J. T., Trudeau, V. et al. 2003. Phytochemical and biological analysis of skullcap (Scutellaria lateriflora L.): a medicinal plant with anxiolytic properties. Phytomedicine, 10: 640-9.

Awad, R., Levac, D., Cybulska, P., Merali, Z., Trudeau, V. L. and Arnason, J. T. 2007a. Effects of traditionally used anxiolytic botanicals on enzymes of the gamma-aminobutyric acid (GABA) system. Can J Physiol Pharmacol, 85: 933-42.

Awad, R., Levac, D., Cybulska, P., Merali, Z., Trudeau, V. L. and Arnason, J. T. 2007b. Effects of traditionally used anxiolytic botanicals on enzymes of the $\gamma$-aminobutyric acid (GABA) system. Canadian Journal of Physiology \& Pharmacology, 85: 933-942.

Awad, R., Muhammad, A., Durst, T., Trudeau, V. L. and Arnason, J. T. 2009. Bioassay-guided fractionation of lemon balm (Melissa officinalis L.) using an in vitro measure of GABA transaminase activity. Phytother Res, 23: 1075-81. 
Baghai, T. C., Volz, H.-P. and Möller, H.-J. 2006. Drug treatment of depression in the 2000s: an overview of achievements in the last 10 years and future possibilities. The World Journal of Biological Psychiatry, 7: $198-222$.

Berk, M., Williams, L. J., Jacka, F. N. et al. 2013. So depression is an inflammatory disease, but where does the inflammation come from? BMC Med, 11: 200.

Bhattacharya, S. K., Bhattacharya, A., Sairam, K. and Ghosal, S. 2000. Anxiolytic-antidepressant activity of Withania somnifera glycowithanolides: an experimental study. Phytomedicine, 7: 463-9.

Bhattacharya, S. K. and Muruganandam, A. V. 2003. Adaptogenic activity of Withania somnifera: an experimental study using a rat model of chronic stress. Pharmacology Biochemistry and Behavior, 75: 547-555.

Boerner, R. J. 2001. Kava kava in the treatment of generalized anxiety disorder, simple phobia and specific social phobia. Phytotherapy Research, 15: 646-647.

Boerner, R. J., Sommer, H., Berger, W., Kuhn, U., Schmidt, U. and Mannel, M. 2003. Kava-Kava extract LI 150 is as effective as Opipramol and Buspirone in Generalised Anxiety Disorder - An 8-week randomized, double-blind multi-centre clinical trial in 129 out-patients. Phytomedicine, 10: 38-49.

Boerth, J. M. and Caley, C. F. 2003. Possible Case of Mania Associated with Ma-Huang. Pharmacotherapy: The Journal of Human Pharmacology and Drug Therapy, 23: 380-383.

Borgert, C. J., Borgert, S. A. and Findley, K. C. 2005. Synergism, antagonism, or additivity of dietary supplements: Application of theory to case studies. Thrombosis Research, 117: 123-132.

Boskabady, M. H. and Farkhondeh, T. 2016. Antiinflammatory, Antioxidant, and Immunomodulatory Effects of Crocus sativus L. and its Main Constituents. Phytother Res, 30: 1072-94.

Bradfield, J. W. B. 2006. A pathologist's perspective of the somatoform disorders. Journal of Psychosomatic Research, 60: 327-330.

Bradwejn, J. M. D. F., Zhou, Y. M. D. P., Koszycki, D. P. and Shlik, J. M. D. P. 2000. A Double-Blind, PlaceboControlled Study on the Effects of Gotu Kola (Centella asiatica) on Acoustic Startle Response in Healthy Subjects. Journal of clinical psychopharmacology, 20: 680-684.

Brock, C., Whitehouse, J., Tewfik, I. and Towell, T. 2014. American Skullcap (Scutellaria lateriflora): a randomised, double-blind placebo-controlled crossover study of its effects on mood in healthy volunteers. Phytother Res, 28: 692-8.

Butterweck, V. 2003. Mechanism of Action of St John's Wort in Depression. CNS Drugs, 17: 539-562.

Bystritsky, A., Kerwin, L. and Feusner, J. D. 2008. A pilot study of Rhodiola rosea (Rhodax) for generalized anxiety disorder (GAD). J Altern Complement Med, 14: 175-80.

Charles, P. D., Ambigapathy, G., Geraldine, P., Akbarsha, M. A. and Rajan, K. E. 2010. Bacopa monniera leaf extract up-regulates tryptophan hydroxylase (TPH2) and serotonin transporter (SERT) expression: Implications in memory formation. Journal of Ethnopharmacology.

Chen, E. Y. and Hui, C. L. 2012. HT1001, a proprietary North American ginseng extract, improves working memory in schizophrenia: a double-blind, placebo-controlled study. Phytother Res, 26: 1166-72.

Chen, X., Hong, Y. and Zheng, P. 2015. Efficacy and safety of extract of Ginkgo biloba as an adjunct therapy in chronic schizophrenia: A systematic review of randomized, double-blind, placebo-controlled studies with meta-analysis. Psychiatry Research, 228: 121-7.

Chengappa, K. N., Bowie, C. R., Schlicht, P. J., Fleet, D., Brar, J. S. and Jindal, R. 2013. Randomized placebocontrolled adjunctive study of an extract of withania somnifera for cognitive dysfunction in bipolar disorder. J Clin Psychiatry, 74: 1076-83. 
Chiavaroli, A., Recinella, L., Ferrante, C. et al. 2017. Crocus sativus, Serenoa repens and Pinus massoniana extracts modulate inflammatory response in isolated rat prostate challenged with LPS. Journal of biological regulators and homeostatic agents, 31: 531-541.

Choudhary, D., Bhattacharyya, S. and Joshi, K. 2017. Body weight management in adults under chronic stress through treatment with Ashwagandha root extract: A double-blind, randomized, placebo-controlled trial. Journal of Evidence-Based Complementary \& Alternative Medicine, 22: 96-106.

Clement, K. M. S. A., Covertson, C. R. P. R. N. C., Johnson, M. J. P. A. and Dearing, K. P. A. 2006. St. John's Wort and the Treatment of Mild to Moderate Depression: A Systematic Review. Holistic Nursing Practice July/August, 20: 197-203.

Cott, J. 2010. St John's wort, Informacare.

Coulter, D. 2007. Assessment of the risk of hepatotoxicity with kava products. WHO appointed committee:

Cropley, M., Banks, A. P. and Boyle, J. 2015. The Effects of Rhodiola rosea L. Extract on Anxiety, Stress, Cognition and Other Mood Symptoms. Phytother Res, 29: 1934-9.

Currier, G. W. and Trenton, A. 2002. Pharmacological Treatment of Psychotic Agitation. CNS Drugs, 16: 219228.

Dantas, L. P., De Oliveira-Ribeiro, A., De Almeida-Souza, L. M. and Groppo, F. C. 2017. Effects of passiflora incarnata and midazolam for control of anxiety in patients undergoing dental extraction. Med Oral Patol Oral Cir Bucal, 22: e95-e101.

Darbinyan, V., Aslanyan, G., Amroyan, E., Gabrielyan, E., Malmstrom, C. and Panossian, A. 2007. Clinical trial of Rhodiola rosea L. extract SHR-5 in the treatment of mild to moderate depression. Nordic journal of psychiatry, 61: 343-8.

Dresser, G. K., Schwarz, U. I., Wilkinson, G. R. and Kim, R. B. 2003. Coordinate induction of both cytochrome P4503A and MDR1 by St John's wort in healthy subjects. Clinical Pharmacology \& Therapeutics, 73: 41-50.

Fahmi, M., Huang, C. and Schweitzer, I. 2002. A Case of Mania Induced by Hyperlcum. The World Journal of Biological Psychiatry, 3: 58-59.

Fava, M. M. D., Alpert, J. M. D. P., Nierenberg, A. a. M. D. et al. 2005. A Double-blind, Randomized Trial of St John's Wort, Fluoxetine, and Placebo in Major Depressive Disorder. Journal of clinical psychopharmacology, 25: 441-447.

Fehske, C. J., Leuner, K. and Muller, W. E. 2009. Ginkgo biloba extract (EGb761) influences monoaminergic neurotransmission via inhibition of NE uptake, but not MAO activity after chronic treatment. Pharmacol Res, 60: 68-73.

Felter, H. W. and Lloyd, J. U. 2006 (1898). King's American Dispensatory.

Findling, R. L., Mcnamara, N. K., O'riordan, M. A. et al. 2003. An Open-Label Pilot Study of St. John's Wort in Juvenile Depression. Journal of the American Academy of Child \& Adolescent Psychiatry, 42: 908-914.

Firoozabadi, A., Zarshenas, M. M., Salehi, A., Jahanbin, S. and Mohagheghzadeh, A. 2015. Effectiveness of Cuscuta planiflora Ten. and Nepeta menthoides Boiss. \& Buhse in major depression: a triple-blind randomized controlled trial study. Journal of Evidence-Based Complementary \& Alternative Medicine, 20: 94-7.

Franklin, M., Hafizi, S., Reed, A., Hockney, R. and Murck, H. 2006. Effect of Sub-Chronic Treatment with Jarsin $^{\circledR}$ (Extract of St John's Wort, Hypericum perforatum) at Two Dose Levels on Evening Salivary Melatonin and Cortisol Concentrations in Healthy Male Volunteers. Pharmacopsychiatry, 39: 13-15.

Gagnier, J. J., Boon, H., Rochon, P. and Et Al. 2006. Reporting randomized, controlled trials of herbal interventions: An elaborated consort statement. Annals of Internal Medicine, 144: 364-367. 
Gordijn, M. C., T Mannetje, D. and Meesters, Y. 2012. The effects of blue-enriched light treatment compared to standard light treatment in Seasonal Affective Disorder. J Affect Disord, 136: 72-80.

Guzelcan, Y., Scholte, W. F., Assies, J. and Becker, H. E. 2001. [Mania during the use of a combination preparation with St. John's wort (Hypericum perforatum)]. Ned Tijdschr Geneeskd, 145: 1943-5.

Hausenblas, H. A., Saha, D., Dubyak, P. J. and Anton, S. D. 2013. Saffron (Crocus sativus L.) and major depressive disorder: a meta-analysis of randomized clinical trials. The Journal of Integrative Medicine, 11: 377-83.

He, X. G., Lin, L. Z. and Lian, L. Z. 1997. Electrospray high performance liquid chromatography-mass spectrometry in phytochemical analysis of kava (Piper methysticum) extract. Planta Med, 63: 70-4.

He, Y., Yue, Y., Zheng, X., Zhang, K., Chen, S. and Du, Z. 2015. Curcumin, inflammation, and chronic diseases: how are they linked? Molecules, 20: 9183-213.

Herrera-Arellano, A., Jimenez-Ferrer, E., Zamilpa, A., Morales-Valdez, M., Garcia-Valencia, C. E. and Tortoriello, J. 2007. Efficacy and tolerability of a standardized herbal product from Galphimia glauca on generalized anxiety disorder. A randomized, double-blind clinical trial controlled with lorazepam. Planta Med, 73: 713-7.

Herrera-Arellano, A., Jiménez-Ferrer, J. E., Zamilpa, A., García-Alonso, G., Herrera-Alvarez, S. and Tortoriello, J. 2012. Therapeutic effectiveness of galphimia glauca vslorazepam in generalized anxiety disorder. A controlled 15-week clinical trial. Planta Medica, 78: 1529-1535.

Hosseinzadeh, H. and Noraei, N. B. 2009. Anxiolytic and hypnotic effect of Crocus sativus aqueous extract and its constituents, crocin and safranal, in mice. Phytother Res, 23: 768-74.

Hunt, C., Slade, T. and Andrews, G. 2004. Generalized Anxiety Disorder and Major Depressive Disorder comorbidity in the National Survey of Mental Health and Well-Being. Depression and Anxiety, 20: 2331.

Hypericum Depression Trial Study, G. 2002. Effect of hypericum perforatum (st john\&\#39;s wort) in major depressive disorder: A randomized controlled trial. JAMA, 287: 1807-1814.

Izzo, A. A. 2004. Drug interactions with St John's wort (Hypericum perforatum): A review of the clinical evidence. Int J Clin Pharmacol Ther, 42: 139-148.

Jana, U., Sur, T. K., Maity, L. N., Debnath, P. K. and Bhattacharyya, D. 2010. A clinical study on the management of generalized anxiety disorder with Centella asiatica. Nepal Medical College journal : NMCJ, 12: 8-11.

Jeong, H. G., Ko, Y. H., Oh, S. Y., Han, C., Kim, T. and Joe, S. H. 2015. Effect of Korean Red Ginseng as an adjuvant treatment for women with residual symptoms of major depression. Asia-Pacific psychiatry: Official Journal of the Pacific Rim College of Psychiatrists, 7: 330-6.

Jimenez-Ferrer, E., Herrera-Ruiz, M., Ramirez-Garcia, R., Herrera-Arellano, A. and Tortoriello, J. 2011. Interaction of the natural anxiolytic Galphimine-B with serotonergic drugs on dorsal hippocampus in rats. Journal of ethnopharmacology, 137: 724-9.

Kaviani, N., Tavakoli, M., Tabanmehr, M. and Havaei, R. 2013. The efficacy of passiflora incarnata linnaeus in reducing dental anxiety in patients undergoing periodontal treatment. J Dent (Shiraz), 14: 68-72.

Keefe, J. R., Mao, J. J., Soeller, I., Li, Q. S. and Amsterdam, J. D. 2016. Short-term open-label chamomile (Matricaria chamomilla L.) therapy of moderate to severe generalized anxiety disorder. Phytomedicine, 23: 1699-1705.

Kelly, G. S. 2001. Rhodiola rosea: a possible plant adaptogen. Altern Med Rev, 6: 293-302.

Kennedy, D. O., Little, W., Haskell, C. F. and Scholey, A. B. 2006. Anxiolytic effects of a combination of Melissa ofcinalis and Valeriana ofcinalis during laboratory induced stress. Phytotherapy Research, 20: 96-102. 
Kennedy, D. O., Scholey, A. B., Tildesley, N. T. J., Perry, E. K. and Wesnes, K. A. 2002. Modulation of mood and cognitive performance following acute administration of Melissa officinalis (lemon balm). Pharmacology Biochemistry and Behavior, 72: 953-964.

Kennedy, D. O. B. P., Little, W. B. and Scholey, A. B. B. P. 2004. Attenuation of Laboratory-Induced Stress in Humans After Acute Administration of Melissa officinalis (Lemon Balm). Psychosomatic Medicine July/August, 66: 607-613.

Kessler, R. C., Berglund, P., Demler, O. and Et Al. 2003. The epidemiology of major depressive disorder: Results from the national comorbidity survey replication (ncs-r). JAMA, 289: 3095-3105.

Kim, N. H., Kim, K. Y., Jeong, H. J. and Kim, H. M. 2011. Antidepressant-like effect of altered Korean red ginseng in mice. Behavioral medicine (Washington, D.C.), 37: 42-6.

Knuppel, L. and Linde, K. 2004. Adverse effects of St. John's Wort: a systematic review. J Clin Psychiatry, 65: 1470-9.

Kobak, K. a. A., Taylor, L. V. H. A., Bystritsky, A. B. et al. 2005a. St John's wort versus placebo in obsessivecompulsive disorder: results from a double-blind study. International Clinical Psychopharmacology, 20: 299-304.

Kobak, K. a. P., Taylor, L. V. H. M. D., Warner, G. M. and Futterer, R. M. D. 2005b. St. John's Wort Versus Placebo in Social Phobia: Results From a Placebo-Controlled Pilot Study. Journal of clinical psychopharmacology, 25: 51-58.

Kolouri, S., Firoozabadi, A., Salehi, A. et al. 2016. Nepeta menthoides Boiss. \& Buhse freeze-dried aqueous extract versus sertraline in the treatment of major depression: A double blind randomized controlled trial. Complementary Therapies in Medicine, 26: 164-70.

Kroenke, K. and Rosmalen, J. G. M. 2006. Symptoms, Syndromes, and the Value of Psychiatric Diagnostics in Patients Who Have Functional Somatic Disorders. Medical Clinics of North America, 90: 603-626.

Kucinskaite, A., Briedis, V. and Savickas, A. 2004. [Experimental analysis of therapeutic properties of Rhodiola rosea L. and its possible application in medicine]. Medicina (Kaunas), 40: 614-9.

Kunnumakkara, A. B., Bordoloi, D., Padmavathi, G. et al. 2017. Curcumin, the golden nutraceutical: multitargeting for multiple chronic diseases. British journal of pharmacology, 174: 1325-1348.

Kuribara, H., Weintraub, S. T., Yoshihama, T. and Maruyama, Y. 2003. An anxiolytic-like effect of Ginkgo biloba extract and its constituent, ginkgolide-A, in mice. J Nat Prod, 66: 1333-7.

Laakmann, G., Schüle, C., Baghai, T. and Kieser, M. 1998. St. John's Wort in Mild to Moderate Depression: The Relevance of Hyperforin for the Clinical Efficacy. Pharmacopsychiatry, 31: 54-59.

Lawvere, S. and Mahoney, M. C. 2005. St. John's wort. Am Fam Physician, 72: 2249-54.

Lecrubier, Y. 2006. Physical components of depression and psychomotor retardation. J Clin Psychiatry, 67 Suppl 6: 23-6.

Linde, K., Berner, M. and Kriston, L. 2008. St John's wort for major depression. Cochrane Database Syst Rev: CD000448.

Linde, K., Mulrow, C. D., Berner, M. and Egger, M. 2005. St John's wort for depression. Cochrane Database Syst Rev: Cd000448.

Lingærde, O., F申reland, A. R. and Magnusson, A. 1999. Can winter depression be prevented by Ginkgo biloba extract? A placebo-controlled trial. Acta Psychiatrica Scandinavica, 100: 62-66.

Lopresti, A. L. 2017. Curcumin for neuropsychiatric disorders: a review of in vitro, animal and human studies. J Psychopharmacol, 31: 287-302.

Lopresti, A. L. and Drummond, P. D. 2017. Efficacy of curcumin, and a saffron/curcumin combination for the treatment of major depression: A randomised, double-blind, placebo-controlled study. J Affect Disord, 207: 188-196. 
Lu, P., Mamiya, T., Lu, L. et al. 2010. Silibinin attenuates cognitive deficits and decreases of dopamine and serotonin induced by repeated methamphetamine treatment. Behavioural Brain Research, 207: 387393.

Maglione, M., Miotto, K., Iguchi, M., Hilton, L. and Shekelle, P. 2005. Psychiatric symptoms associated with ephedra use. Expert Opinion on Drug Safety, 4: 879-884.

Magnusson, A. and Partonen, T. 2005. The diagnosis, symptomatology, and epidemiology of seasonal affective disorder. CNS Spectr, 10: 625-34; quiz 1-14.

Magura, E., Kopanitsa, M., Gleitz, J. and Al., E. 1997. Kava extract ingredients (+)-methysticin and (+/-)kavain inhibit voltage-operated $\mathrm{Na}(+)$-channels in rat CA1 hippocampal neurons. Neuroscience, 81: $345-351$.

Mao, J. J., Xie, S. X., Keefe, J. R., Soeller, I., Li, Q. S. and Amsterdam, J. D. 2016. Long-term chamomile (Matricaria chamomilla L.) treatment for generalized anxiety disorder: A randomized clinical trial. Phytomedicine, 23: 1735-1742.

Mao, J. J., Xie, S. X., Zee, J. et al. 2015. Rhodiola rosea versus sertraline for major depressive disorder: A randomized placebo-controlled trial. Phytomedicine, 22: 394-9.

Martinez, B., Kasper, S., Ruhrmann, S. and Moller, H. J. 1994. Hypericum in the treatment of seasonal affective disorders. Journal of Geriatric Psychiatry \& Neurology, 7 Suppl 1: S29-33.

Mathews, J., Etheridge, A., Valentine, J. and Al., E. 2005. Pharmacokinetics and disposition of the kavalactone kawain: interaction with kava extract and kavalactones in vivo and in vitro. Drug Metab Dispos.: 1555 - 1563.

Mazidi, M., Shemshian, M., Mousavi, S. H. et al. 2016. A double-blind, randomized and placebo-controlled trial of Saffron (Crocus sativus L.) in the treatment of anxiety and depression. Journal of complementary \& integrative medicine, 13: 195-9.

Melzer, J., Schrader, E., Brattstrom, A., Schellenberg, R. and Saller, R. 2009. Fixed herbal drug combination with and without butterbur (Ze 185) for the treatment of patients with somatoform disorders: randomized, placebo-controlled pharmaco-clinical trial. Phytother Res, 23: 1303-8.

Mennini, T. and Gobbi, M. 2004. The antidepressant mechanism of Hypericum perforatum. Life Sciences, 75: 1021-1027.

Mohr, P., Pecenak, J., Svestka, J., Swingler, D. and Treuer, T. 2005. Treatment of acute agitation in psychotic disorders. Neuro Endocrinol Lett, 26: 327-35.

Moore, L. B., Goodwin, B., Jones, S. A. et al. 2000. St. John's wort induces hepatic drug metabolism through activation of the pregnane $X$ receptor. Proceedings of the National Academy of Sciences, 97: 75007502.

Movafegh, A., Alizadeh, R., Hajimohamadi, F., Esfehani, F. and Nejatfar, M. 2008. Preoperative oral Passiflora incarnata reduces anxiety in ambulatory surgery patients: a double-blind, placebo-controlled study. Anesthesia and analgesia, 106: 1728-32.

Mueller, S. C., Majcher-Peszynska, J., Uehleke, B. et al. 2006. The extent of induction of CYP3A by St. John's wort varies among products and is linked to hyperforin dose. European Journal of Clinical Pharmacology, 62: 29-36.

Müller, D., Pfeil, T. and Von Den Driesch, V. 2003. Treating depression comorbid with anxiety - results of an open, practice-oriented study with St John's wort WS ${ }^{\circledR} 5572$ and valerian extract in high doses. Phytomedicine, 10: 25-30.

Muller, S. F. and Klement, S. 2006. A combination of valerian and lemon balm is effective in the treatment of restlessness and dyssomnia in children. Phytomedicine, 13: 383-7. 
Muller, T. M. D., Mannel, M. M. D., Murck, H. M. D. and Rahlfs, V. W. C. 2004. Treatment of Somatoform Disorders With St. John's Wort: A Randomized, Double-Blind and Placebo-Controlled Trial. Psychosomatic Medicine July/August, 66: 538-547.

Nassiri-Asl, M., Zamansoltani, F. and Shariati-Rad, S. 2008. Possible role of GABAA-benzodiazepine receptor in anticonvulsant effects of Pasipay in rats. Zhong Xi Yi Jie He Xue Bao, 6: 1170-3.

Nemeroff, C. B. 2003. Improving antidepressant adherence. J Clin Psychiatry, 64 Suppl 18: 25-30.

Ng, Q. X., Koh, S. S. H., Chan, H. W. and Ho, C. Y. X. 2017. Clinical Use of Curcumin in Depression: A MetaAnalysis. Journal of the American Medical Directors Association, 18: 503-508.

Nierenberg, A. A., Burt, T., Matthews, J. and Weiss, A. P. 1999. Mania associated with St. John's wort. Biological Psychiatry, 46: 1707-1708.

Nikfarjam, M., Parvin, N., Assarzadegan, N. and Asghari, S. 2013. The Effects of Lavandula Angustifolia Mill Infusion on Depression in Patients Using Citalopram: A comparison Study. Iranian Red Crescent medical journal, 15: 734-9.

Nikfarjam, M., Rakhshan, R. and Ghaderi, H. 2017. Comparison of Effect of Lavandula officinalis and Venlafaxine in Treating Depression: A Double Blind Clinical Trial. Journal of clinical and diagnostic research : JCDR, 11: KC01-KC04.

Olsson, E. M., Von Scheele, B. and Panossian, A. G. 2009. A randomised, double-blind, placebo-controlled, parallel-group study of the standardised extract shr- 5 of the roots of Rhodiola rosea in the treatment of subjects with stress-related fatigue. Planta Med, 75: 105-12.

Osuchowski, M. F., Johnson, V. J., He, Q. and Sharma, R. P. 2004. Alterations in regional brain neurotransmitters by silymarin, a natural antioxidant flavonoid mixture, in BALB/c mice. Pharmaceutical Biology, 42: 384-389.

Pakseresht, S., Boostani, H. and Sayyah, M. 2011. Extract of valerian root (Valeriana officinalis L.) vs. placebo in treatment of obsessive-compulsive disorder: a randomized double-blind study. Journal of complementary \& integrative medicine, 8.

Pittler, M. H. and Ernst, E. 2003. Kava extract for treating anxiety. Cochrane Database of Systematic Reviews: CD003383.

Pratte, M. A., Nanavati, K. B., Young, V. and Morley, C. P. 2014. An alternative treatment for anxiety: a systematic review of human trial results reported for the Ayurvedic herb ashwagandha (Withania somnifera). J Altern Complement Med, 20: 901-8.

Rahimi, R., Nikfar, S. and Abdollahi, M. 2009. Efficacy and tolerability of Hypericum perforatum in major depressive disorder in comparison with selective serotonin reuptake inhibitors: a meta-analysis. Prog Neuropsychopharmacol Biol Psychiatry, 33: 118-27.

Randløv, C., Mehlsen, J., Thomsen, C. F., Hedman, C., Von Fircks, H. and Winther, K. 2006. The efficacy of St. John's Wort in patients with minor depressive symptoms or dysthymia - a double-blind placebocontrolled study. Phytomedicine, 13: 215-221.

Rodriguez-Landa, J. F. and Contreras, C. M. 2003. A review of clinical and experimental observations about antidepressant actions and side effects produced by Hypericum perforatum extracts. Phytomedicine, 10: 688-99.

Sahraian, A., Jelodar, S., Javid, Z., Mowla, A. and Ahmadzadeh, L. 2016. Study the effects of saffron on depression and lipid profiles: A double blind comparative study. Asian Journal of Psychiatry, 22: 1746.

Salehi, B., Imani, R., Mohammadi, M. R. et al. 2010. Ginkgo biloba for Attention-Deficit/Hyperactivity Disorder in children and adolescents: A double blind, randomized controlled trial. Progress in NeuroPsychopharmacology and Biological Psychiatry, 34: 76-80. 
Salgueiro, J. B., Ardenghi, P., Dias, M., Ferreira, M. B. C., Izquierdo, I. and Medina, J. H. 1997. Anxiolytic natural and synthetic flavonoid ligands of the central benzodiazepine receptor have no effect on memory tasks in rats. Pharmacology Biochemistry and Behavior, 58: 887-891.

Sarris, J. 2007. Herbal medicines in the treatment of psychiatric disorders: a systematic review. Phytother Res, 21: 703-16.

Sarris, J., Fava, M., Schweitzer, I. and Mischoulon, D. 2012. St John's wort (Hypericum perforatum) versus sertraline and placebo in major depressive disorder: continuation data from a 26-week RCT. Pharmacopsychiatry, 45: 275-8.

Sarris, J., Kavanagh, D. J., Byrne, G., Bone, K. M., Adams, J. and Deed, G. 2009a. The Kava Anxiety Depression Spectrum Study (KADSS): a randomized, placebo-controlled crossover trial using an aqueous extract of Piper methysticum. Psychopharmacology. pp. 399-407.

Sarris, J., Kavanagh, D. J., Deed, G. and Bone, K. M. 2009b. St. John's wort and Kava in treating major depressive disorder with comorbid anxiety: a randomised double-blind placebo-controlled pilot trial. Human psychopharmacology, 24: 41-8.

Sarris, J., Mcintyre, E. and Camfield, D. A. 2013a. Plant-based medicines for anxiety disorders, Part 1: a review of preclinical studies. CNS Drugs, 27: 207-19.

Sarris, J., Mcintyre, E. and Camfield, D. A. 2013b. Plant-based medicines for anxiety disorders, part 2: a review of clinical studies with supporting preclinical evidence. CNS Drugs, 27: 301-19.

Sarris, J., Panossian, A., Schweitzer, I., Stough, C. and Scholey, A. 2011. Herbal medicine for depression, anxiety and insomnia: a review of psychopharmacology and clinical evidence. Eur Neuropsychopharmacol, 21: 841-60.

Sarris, J., Stough, C., Bousman, C. A. et al. 2013c. Kava in the treatment of generalized anxiety disorder: a double-blind, randomized, placebo-controlled study. Journal of clinical psychopharmacology, 33: 643-8.

Sartorius, N., Ustun, T. B., Lecrubier, Y. and Wittchen, H. U. 1996. Depression comorbid with anxiety: results from the WHO study on psychological disorders in primary health care. Br J Psychiatry Suppl: 38-43.

Sayyah, M., Boostani, H., Pakseresht, S. and Malayeri, A. 2010a. Comparison of Silybum marianum (L.) Gaertn. with fluoxetine in the treatment of Obsessive-Compulsive Disorder. Progress in NeuroPsychopharmacology and Biological Psychiatry, 34: 362-365.

Sayyah, M., Boostani, H., Pakseresht, S. and Malayeri, A. 2010b. Comparison of Silybum marianum (L.) Gaertn. with fluoxetine in the treatment of Obsessive-Compulsive Disorder. Prog Neuropsychopharmacol Biol Psychiatry, 34: 362-5.

Schmidt, M., Betti, G. and Hensel, A. 2007. Saffron in phytotherapy: pharmacology and clinical uses. Wiener medizinische Wochenschrift (1946), 157: 315-9.

Schüle, C., Baghai, T., Ferrera, A. and Laakmann, G. 2001. Neuroendocrine Effects of Hypericum Extract WS 5570 in 12 Healthy Male Volunteers. Pharmacopsychiatry, 34: 127-133.

Schulz, V. 2006. Safety of St. John's Wort extract compared to synthetic antidepressants. Phytomedicine, 13: 199-204.

Shahmansouri, N., Farokhnia, M., Abbasi, S. H. et al. 2014. A randomized, double-blind, clinical trial comparing the efficacy and safety of Crocus sativus L. with fluoxetine for improving mild to moderate depression in post percutaneous coronary intervention patients. J Affect Disord, 155: 21622.

Sheehan, D., Lecrubier, Y., Sheehan, K. et al. 1998. The Mini-International Neuropsychiatric Interview (M.I.N.I.): the development and validation of a structured diagnostic psychiatric interview for DSMIV and ICD-10. Journal of Clinical Psychiatry, 59: 34-57. 
Shelton, R. C., Keller, M. B., Gelenberg, A. and Et Al. 2001. Effectiveness of st john\&\#39;s wort in major depression: A randomized controlled trial. JAMA, 285: 1978-1986.

Shevtsov, V. A., Zholus, B. I., Shervarly, V. I. et al. 2003. A randomized trial of two different doses of a SHR-5 Rhodiola rosea extract versus placebo and control of capacity for mental work. Phytomedicine, 10: 95-105.

Simeon, J., Nixon, M. K., Milin, R., Jovanovic, R. and Walker, S. 2005. Open-label pilot study of St. John's wort in adolescent depression. Journal of child and adolescent psychopharmacology, 15: 293-301.

Singh, H. K. and Dhawan, B. N. 1997. Neuropsychopharmacological effects of the ayurvedic nootropic Bacopa monniera Linn. (Brahmi). Indian Journal of Pharmacology, 29: S359-S365.

Spinella, M. and Eaton, L. A. 2002. Hypomania induced by herbal and pharmaceutical psychotropic medicines following mild traumatic brain injury. Brain Injury, 16: 359-367.

Stevinson, C. and Ernst, E. 2004. Can St. John's wort trigger psychoses? Int J Clin Pharmacol Ther, 42: 473-80.

Stevinson, C., Huntley, A. and Ernst, E. 2002. A Systematic Review of the Safety of Kava Extract in the Treatment of Anxiety. Drug Safety, 25: 251-261.

Stough, C., Lloyd, J., Clarke, J. et al. 2001. The chronic effects of an extract of Bacopa monniera (Brahmi) on cognitive function in healthy human subjects. Psychopharmacology, 156: 481-484.

Szegedi, A., Kohnen, R., Dienel, A. and Kieser, M. 2005. Acute treatment of moderate to severe depression with hypericum extract WS 5570 (St John's wort): randomised controlled double blind non-inferiority trial versus paroxetine. Bmj, 330: 503.

Taylor, L. H. and Kobak, K. A. 2000. An open-label trial of St. John's Wort (Hypericum perforatum) in obsessive-compulsive disorder. J Clin Psychiatry, 61: 575-8.

Teschke, R., Sarris, J., Glass, X. and Schulze, J. 2011a. Kava, the anxiolytic herb: back to basics to prevent liver injury? Br J Clin Pharmacol, 71: 445-8.

Teschke, R., Sarris, J. and Lebot, V. 2011b. Kava hepatotoxicity solution: A six-point plan for new kava standardization. Phytomedicine, 18: 96-103.

Van Diermen, D., Marston, A., Bravo, J., Reist, M., Carrupt, P. A. and Hostettmann, K. 2009. Monoamine oxidase inhibition by Rhodiola rosea L. roots. Journal of ethnopharmacology, 122: 397-401.

Vazquez, I. and Aguera-Ortiz, L. F. 2002. Herbal products and serious side effects: a case of ginseng-induced manic episode. Acta Psychiatr Scand, 105: 76-7; discussion 77-8.

Viola, H., Wasowski, C., Levi De Stein, M. et al. 1995. Apigenin, a component of Matricaria recutita flowers, is a central benzodiazepine receptors-ligand with anxiolytic effects. Planta Med, 61: 213-6.

Volz, H.-P., Murck, H., Kasper, S. and Möller, H.-J. 2002. St John's wort extract (LI 160) in somatoform disorders: results of a placebo-controlled trial. Psychopharmacology, 164: 294-300.

Weber, W., Vander Stoep, A., Mccarty, R. L., Weiss, N. S., Biederman, J. and Mcclellan, J. 2008. Hypericum perforatum (St John's Wort) for attention-deficit/hyperactivity disorder in children and adolescents: A randomized controlled trial. JAMA - Journal of the American Medical Association, 299: 2633-2641.

Wei, X. Y., Yang, J. Y., Wang, J. H. and Wu, C. F. 2007. Anxiolytic effect of saponins from Panax quinquefolium in mice. Journal of ethnopharmacology, 111: 613-8.

Wheatley, D. 1999. Hypericum in Seasonal Affective Disorder (SAD). Current Medical Research and Opinion, 15: 33-37.

Who. 2006. Mental Health 'Depression'. .

Williamson, E. M. 2001. Synergy and other interactions in phytomedicines. Phytomedicine, 8: 401-9.

Woelk, H., Arnoldt, K. H., Kieser, M. and Hoerr, R. 2007. Ginkgo biloba special extract EGb $761^{\circledR}$ in generalized anxiety disorder and adjustment disorder with anxious mood: A randomized, doubleblind, placebo-controlled trial. Journal of Psychiatric Research, 41: 472-480. 
Woelk, H. and Schlafke, S. 2010. A multi-center, double-blind, randomised study of the Lavender oil preparation Silexan in comparison to Lorazepam for generalized anxiety disorder. Phytomedicine, 17: 94-9.

Wohlmuth, H., Penman, K. G., Pearson, T. and Lehmann, R. P. 2010. Pharmacognosy and chemotypes of passionflower (Passiflora incarnata L.). Biol Pharm Bull, 33: 1015-8.

Wolfson, P. and Hoffmann, D. L. 2003. An investigation into the efficacy of Scutellaria lateriflora in healthy volunteers. Alternative therapies in health and medicine, 9: 74-8.

Wong, A. C., Smith, M. and Boon, H. S. 1998. Herbal remedies in psychiatric practice. Archives of General Psychiatry, 55: 1033-1044.

Wurglics, M. and Schubert-Zsilavecz, M. 2006. Hypericum Perforatum: A 'Modern' Herbal Antidepressant. Clinical Pharmacokinetics, 45: 449-468.

Yu, J. J., Pei, L. B., Zhang, Y., Wen, Z. Y. and Yang, J. L. 2015. Chronic Supplementation of Curcumin Enhances the Efficacy of Antidepressants in Major Depressive Disorder: A Randomized, Double-Blind, PlaceboControlled Pilot Study. J Clin Psychopharmacol, 35: 406-10.

Zanoli, P. 2004. Role of Hyperforin in the Pharmacological Activities of St. John's Wort. CNS Drug Reviews, 10: 203-218.

This article is protected by copyright. All rights reserved. 
Table 1. Psychiatric conditions reviewed

\section{DISORDER}

Mood disorders

Major depressive disorder

Dysthymic disorder

Anxious depression

Seasonal affective disorder

Bipolar disorder

Anxiety disorders

Generalized anxiety disorder

Social phobia

Obsessive-compulsive disorder

Somatoform disorder

Schizophrenia

Attention-Deficit Hyperactivity Disorder

This article is protected by copyright. All rights reserved. 
Table 2. Herbal medicines reviewed

\section{Herbal medicine}

Bacopa monniera

Centella asiatica

Citrus aurantium

Crocus sativus

Curcuma longa

Cuscuta spp.

Hypericum perforatum

Galphimia glauca

Ginkgo biloba

Lavandula spp.

Matricaria recutita

Melissa officinalis

Nepeta spp.

Panax ginseng

Panax quinquefolium

Passiflora incarnata

Petasites hybridus

Pinus pinaster

Piper methysticum

Rhodiola rosea

Scutellaria lateriflora

Silybum marianum

Valeriana spp.

Withania somnifera

\section{Psychiatric Disorders/Symptoms Studied}

GAD

Generalized anxiety and stress, GAD

GAD

MDD, GAD

MDD

MDD

MDD, SP, OCD, ADHD, DYS, SOM, SAD, AnxD

GAD

GAD, SAD, ADHD, BD

MDD

GAD

Generalized anxiety, stress, mood disturbance, SOM

GAD

MDD, GAD

$\mathrm{SCHZ}, \mathrm{ADHD}$

GAD, SOM

SOM

ADHD

GAD, SP, AnxD

MDD, GAD

GAD

OCD

GAD, AnxD, SOM

$\mathrm{SCHZ}, \mathrm{BD}, \mathrm{GAD}$

$\mathrm{GAD}=$ Generalized Anxiety Disorder; $\mathrm{MDD}=$ Major Depressive Disorder; $\mathrm{SCHZ}=$ Schizophrenia; $\mathrm{OCD}=$ Obsessive-Compulsive Disorder; $\mathrm{SP}=$ Social Phobia; $\mathrm{DYS}=$

This article is protected by copyright. All rights reserved. 
Dysthymia; SOM= Somatoform Disorder; SAD= Seasonal Affective Disorder; BD= Bipolar Disorder; AnxD= Anxious Depression

This article is protected by copyright. All rights reserved. 


\section{University Library}

\section{- M M N E R VA A gateway to Melbourne's research publications}

Minerva Access is the Institutional Repository of The University of Melbourne

Author/s:

Sarris, J

Title:

Herbal medicines in the treatment of psychiatric disorders: 10-year updated review

Date:

2018-07-01

Citation:

Sarris, J. (2018). Herbal medicines in the treatment of psychiatric disorders: 10year updated review. PHYTOTHERAPY RESEARCH, 32 (7), pp.1147-1162. https:// doi.org/10.1002/ptr.6055.

Persistent Link:

http://hdl.handle.net/11343/283764 